\title{
As impurezas da ditadura militar
}

\section{Carla Cristiane Martins Vianna*}

Resumo: O presente trabalho pretende investigar em alguns poemas de As impurezas do branco a enunciação da realidade brasileira de então, perceptível através da ironia e do desencanto deste eulírico. Partindo do pressuposto de Candido de que em poesia o trabalho do poeta é desfazer e refazer o mundo, percorreremos os versos de Drummond em busca do mundo refeito por ele.

Palavras-chave: Poesia; Ditadura; Cerceamento.

\begin{abstract}
This study aims at looking into some poems from As impurezas do branco in order to find out the enunciation of the Brazilian reality of that time, which is noticeable due to the irony and the disenchantment shown by this lyric self. From the idea proposed by Antonio Candido, who believed that the poet's task was to undo and refashion the world, we checked up on Drummond's verses in search of the universe he has remodeled.
\end{abstract}

Keywords: Poetry; Dictatorship; Censorship.

\section{o Começando pelo começo}

Carlos Drummond de Andrade é o poeta do inquestionável A rosa do povo, livro de versos compostos no calor da ditadura getulista e da Segunda Guerra Mundial, versos representativos do melhor de sua poesia. Nele, Drummond atingiu um dos propósitos da literatura - e da arte em geral -, que é tratar de temáticas sociais sem cair na vala comum do texto panfletário. Assim como para o artista não é tarefa fácil fugir da arte panfletária, o crítico muitas vezes também não consegue fugir da tentação de tratar como documento um texto, quando a sua preocupação é considerar o contexto social de tal obra. É Antonio Candido (1996, p.30) quem aborda com maestria este dilema da crítica literária:

Como estudar o texto literário levando em conta o seu vínculo com as motivações exteriores, provindas da personalidade ou da sociedade, sem cair no paralelismo, que leva a tratá-lo como documento? A única maneira talvez seja entrar pela própria constituição do discurso, desmontando-o como se a escrita gerasse um universo próprio. E a verificação básica a este respeito é que o autor pode manipular a palavra em dois sentidos principais: reforçando ou atenuando a sua semelhança com o mundo real.

\footnotetext{
* Carla Cristiane Martins Vianna é mestranda em Literatura Brasileira pela Universidade Federal do Rio Grande do Sul.
} 
A "análise do universo próprio da obra literária" e a sua relação com as "motivações exteriores" será o caminho percorrido por este breve ensaio, que se detém no livro As impurezas do branco, publicado por Carlos Drummond de Andrade em 1973. A leitura do ensaio "O mundo desfeito e refeito"(CANDIDO, 1996) foi decisiva para a realização deste, tendo em vista que as palavras do autor parecem sugerir um modo de investigação do texto literário que possibilita a compreensão da obra poética em questão.

Convém lembrarmos que, além da capacidade de enunciação dos problemas da matéria brasileira, o poeta gauche também era mestre em tratar de temáticas universais. E, neste livro, continua poetizando o amor, a morte, a crença, a saudade. Nele, Carlos Drummond de Andrade versifica os mais diversos temas, por isso foi preciso direcionar a discussão para que fosse feita uma análise mais atenciosa.

O intuito deste ensaio é verificar como o sujeito lírico de Drummond trata o período ditatorial brasileiro. Para isso, teremos como corpus os poemas: "Diamundo", "Confissão", "Declaração em juízo" e, finalmente, "Paisagem: como se faz". Uns serão discutidos mais detalhadamente do que outros, mas todos foram selecionados por representarem bem o empenho de Drummond em tratar da vida social brasileira num período tão complicado para se fazer isto.

\section{Drummond: o poeta oculto}

No segundo poema de As impurezas do branco, "Diamundo" - cujo subtítulo é "24 H de informação na vida do jornaledor" -, encontramos 320 versos que ilustram ironicamente as manchetes ou as notícias de um jornal brasileiro no auge da ditadura militar. Os versos iniciais do poema são uma relação da previsão do tempo em várias capitais, relação esta que é encerrada com o seguinte verso: "- cariocas terão praia espetacular".(1974, p. 8)

Todo leitor de jornal já passou os olhos, alguma vez na vida, pela seção de previsão do tempo, portanto a novidade do poema está no verso acima citado, pois é por meio dele que podemos perceber a visada irônica, até então imperceptível, deste eu-lírico. É de uma forma sutil como essa que percebemos a ironia de Drummond, que numa leitura desatenta pode passar por um reles apanhado de manchetes corriqueiras ou exóticas. Para melhor entendermos o funcionamento deste poema, transcreveremos a segunda e ótima estrofe:

Índice de poluição

na Rodoviária de São Paulo:

12:6 satisfatório

Na Rua Tamandaré 693:

15:7 insatisfatório 
Recorde de partículas no centro do Rio de Janeiro em torno do palácio da Justiça. (1974, p. 8)

O leitor não pode ser ingênuo a ponto de considerar que a localidade onde o índice de poluição bate recorde foi aleatoriamente escolhida por Drummond. O leitor não é ingênuo e sabe que As impurezas do branco foi publicado em 1973, em pleno governo Médici, assim como sabe que aqueles não eram tempos justos. Drummond sabia que os tempos de completa justiça ainda não haviam chegado, prova disto são os poemas que estamos analisando ; neles, o poeta mineiro clamava por mais justiça e liberdade. Afonso Arinos de Melo Franco (1978, p.86) reconheceu essa característica na poesia de Carlos Drummond de Andrade:

Mas o que interessa salientar é a integração do poeta nos problemas do mundo. Neste ponto ele é o mais importante dos poetas brasileiros atuais. Talvez o mais capaz de colocar seus poemas a serviço das novas aspirações humanas de justiça e liberdade, tal como Castro Alves fez no seu tempo.

Ainda em "Diamundo", encontramos versos em que há uma crítica mais contundente, mais explícita, à injustiça, como podemos ler nos versos abaixo:

Polícia Federal no Rio Grande do Norte

apreende caminhão com 55 lavradores

vendidos ao preço unitário de 60 cruzeiros

ao fazendeiro Zé Ricota de Goiás (1974, p. 13)

A crítica à sociedade de consumo dos tempos da ditadura é clara neste poema, como em outros do livro. E esta crítica é feita através da ironia do eu-lírico, que, não raro, faz piada com intenção de denunciar. Vejamos:

\author{
Pode-se admitir \\ nos dias que vivemos \\ paquerar sem carro? \\ Revendedor Relâmpago resolve
}

Se Rui Barbosa desse aulas em cursinho seria neste aqui (1974, p. 11-12)

Elio Gaspari (2002, p. 470) recolheu uma manchete do The New York Times que se assemelha bastante aos versos de "Diamundo", vejamos: "o regime é antipatizado, mas o Brasil cresce". A coordenação destas idéias dá à frase uma falsa ilusão de que estamos sendo informados dos fatos, quando na verdade ela vem impregnada ideologicamente e afirma discretamente que o crescimento do Brasil supera qualquer antipatia ao regime. Procedimentos jornalísticos como este, colaboravam para que a ditadura militar se mantivesse no poder, colaboração imperceptível a mentes desavisadas, mas poderosa.

Nestes 320 versos, Drummond aponta injustiças, ironiza e alude ao preconceito, à alienação, ao consumismo, ao jogo de interesses, mas não cria nenhuma manchete que envolva o governo ditatorial e tudo o que ele traz consigo, como a falta de liberdade, a tortura. 
A isso ele não se refere explicitamente, porque a presença da ditadura neste poema, como no livro, é uma presença marcada pela ausência. O poeta criticava sim a ditadura, porém esta era uma crítica mais velada, menos óbvia, mas não menos intensa. No poema "Confissão", há dois versos que vão ao encontro desse argumento:

como é trinta vezes certo que me oculto no meu grito $(1974$, p. 23$)$

Ao longo de "Confissão", o sujeito lírico informa ao leitor aquilo que é certo:

É certo que me repito

é certo que me refuto

e que, decidido, hesito

no entra-e-sai de um minuto. (1974, p. 23)

Este eu-lírico está nos dizendo que é certo que ele se repete, refuta e que mesmo decidido, hesita. Porém, nada é mais certo do que o fato deste eu ocultar-se em seu grito. Se o resto era certo, ocultar-se no seu grito era trinta vezes certo para este eu que nos fala. Imagem paradoxal esta, tendo em vista que ninguém em sã consciência grita quando deseja esconderse, já que, através do grito, podemos localizar a pessoa que grita.

Ao invés de um mero paradoxo, temos uma bela imagem, que pode ser interpretada como uma alegoria da própria poesia de Carlos Drummond de Andrade naquele momento histórico. Gritando ele se ocultava, assim como versejando ele gritava (protestava, criticava) de um modo que era possível permanecer escondido ou não ser facilmente encontrado.

Uma das lições que se tira ao lermos este livro é o conhecimento do quão ignorantes eram os fiscais da censura, pelo menos quando o assunto era a poesia de Carlos Drummond de Andrade. Isso o ajudava a ocultar-se no seu grito. Em 1968, Luiz Costa Lima competentemente afirmou:

Ao correr de sua produção, Carlos Drummond oscilará diante do problema. Em uma época politizará sua palavra, fazendo-a instrumento de rebeldia contra a ordem-desordem. Depois, mais recentemente, calará, camuflará sua resposta, recaindo no seu velho ouriço individualista. Mas não há silêncio para quem saiba ler por debaixo da impregnação ideológica. A guerra, quando não esteja denunciada, subsistirá tácita. (LIMA, 1968, p. 159)

É esta a postura do poeta Drummond: denunciar veladamente a guerra. A própria poesia era trabalhada de modo que encobrisse a sua realidade ideológica, isto é, o artista deveria criar de maneira que não ficasse explícito o seu posicionamento, a menos que este fosse de adesão ao regime. Por isso, ele foi um sobrevivente, pois, além do cidadão Carlos Drummond de Andrade não ter caído nas garras dos cruéis departamentos da ditadura, o poeta Drummond continuava a compor seus versos, recusando-se ao cômodo silêncio. 


\section{Paisagem declarada}

De suma importância para a compreensão de sua poesia nos anos de chumbo da ditadura militar brasileira é o poema "Declaração em juízo", que será transcrito na íntegra para facilitar a nossa reflexão:

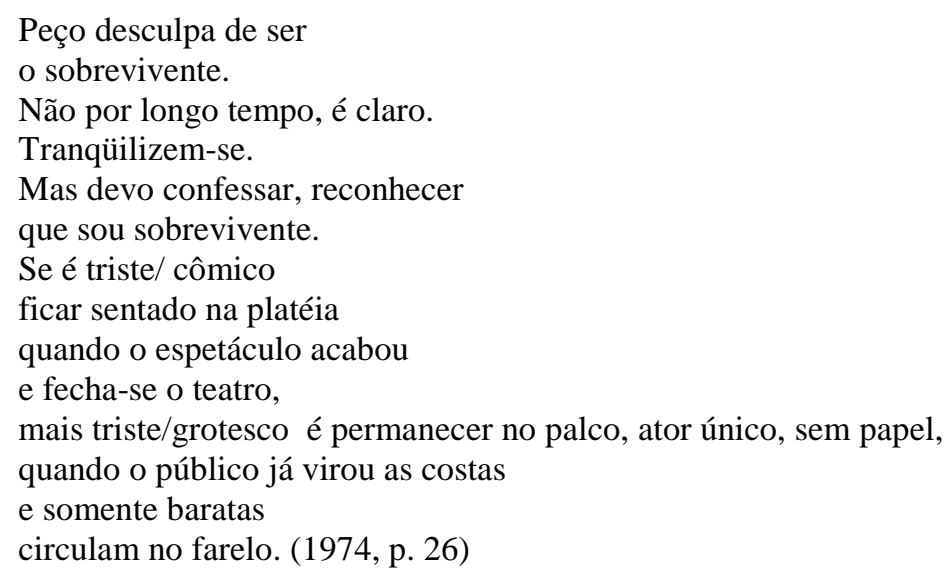

Nesta primeira estrofe do poema, o eu-lírico pede desculpas por ter sobrevivido, ao passo que o leitor se pergunta: sobreviveu a quê? Pergunta que o eu-lírico recusa-se a responder abertamente, ou seja, a resposta está oculta no poema, tendo em vista que aqueles eram tempos em que era muito arriscado o exercício da sinceridade, da transparência. É preciso que atentemos para o fato de que este eu, não contente em desculpar-se, decidiu também confessar-se um sobrevivente. E ser um sobrevivente na era Médici era algo que causava certa culpa e uma inevitável sensação de solidão, já que os sobreviventes eram raros. Aqui, o eu-lírico acusa-se como "o sobrevivente".

Podemos intuir ainda que esse sujeito lírico não era um sobrevivente passivo ante a realidade, pois não ficou sentado na platéia quando o espetáculo acabou, mas optou por permanecer no palco, mesmo sem papel e quando o público já tinha virado as costas. A propósito, podemos nos perguntar: qual era então o papel do poeta? Será que não era um ator sem papel a permanecer no palco?

"Declaração em juízo" é um poema que pode ser lido como um desabafo crítico sobre os sofrimentos de um sobrevivente da ditadura militar, mas também como um desabafo lamentoso e nostálgico de um velho poeta (Drummond tinha 71 anos em 1973). A primeira leitura será a privilegiada neste trabalho. Continuemos:

Reparem: não tenho culpa.

Não fiz nada para ser sobrevivente.

Não roguei aos altos poderes

que me conservassem tanto tempo. 
Não matei nenhum dos companheiros.

Se não saí violentamente,

se me deixei ficar ficar ficar,

foi sem segunda intenção. $(1974$, p. 26)

Se ele não se sentia culpado, por que pediu desculpa e confessou-se na estrofe anterior? Eis que podemos vislumbrar aqui um sujeito lírico preocupado com a imagem que os outros têm dele, pois desmente de antemão as possíveis acusações que poderia sofrer. Mas, sobretudo, devemos perceber nestes versos uma manifestação da antiga culpa drummondiana, tão bem desenhada por Vagner Camilo (2001, p. 247):

A perda de status, se implica depauperização, não chega a igualar o filho de fazendeiro ao nível daqueles a quem dirige seu apelo solidário, seja o operário, o habitante do morro, ou do subúrbio. A distância social persiste e é da consciência de sua insuperabilidade - portanto da impossibilidade de identificação integral - que redunda a culpa social.

Cabe ressaltar que não era apenas a consciência da distância social que fazia o poeta sentir-se culpado, mas o seu alto cargo como funcionário público também o fazia sentir-se desconfortável desde os tempos de A rosa do povo (1945). Aqui, em plena ditadura, o então aposentado Drummond sente a necessidade de afirmar que não rogou aos altos poderes que o ajudassem a sobreviver, assim como também não matou nenhum companheiro. O eu-lírico deixa bem claro de quem é companheiro: daqueles que estão partindo ou morrendo, e não daqueles que estão matando.

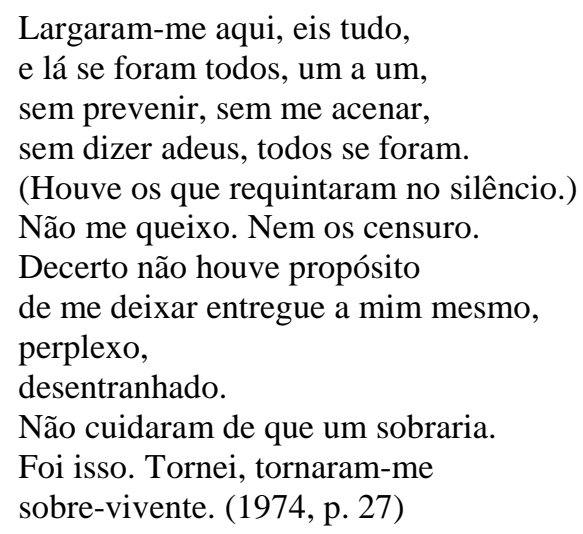

Nessas primeiras estrofes, podemos perceber que o eu-lírico coloca-se numa posição passiva; em outras palavras, é aquele que sofre a ação de outros. Ele não é o culpado de ser o único sobrevivente, pois foi largado por aqueles que se foram: forte ironia do sujeito lírico, pois se tivesse sido abandonado, não haveria motivo para estar pedindo perdão, explicando-se.

O leitor deve se perguntar o porquê de todos partirem sem aviso, sem aceno, sem adeus. Repentinamente, este eu-lírico está solitário, pois, além do distanciamento físico, há também a distância imposta pelo silêncio daqueles que ficaram e requintaram no silêncio. 
Distância, solidão e silêncio eram palavras cotidianas no governo Médici, época da ditadura escancarada, segundo Elio Gaspari (2002).

Naquela época de ditadura escancarada, Caetano Veloso e Gilberto Gil ficaram exilados em Londres, Chico Buarque na Itália, Caio Prado Júnior foi condenado a quatro anos e meio de prisão, enfim, a cultura e o pensamento brasileiros estavam sendo brutalmente cerceados pelos militares através de órgãos como o DOPS, o DOI e outros tantos que faziam parte da burocracia ditatorial. Inserido neste contexto, o poeta gauche era realmente um sobrevivente, por permanecer no país e, além disso, sobreviver, tendo em vista que não se refugiou no silêncio, não se sentou na platéia, mas permaneceu no palco, publicando versos como estes que estamos lendo agora.

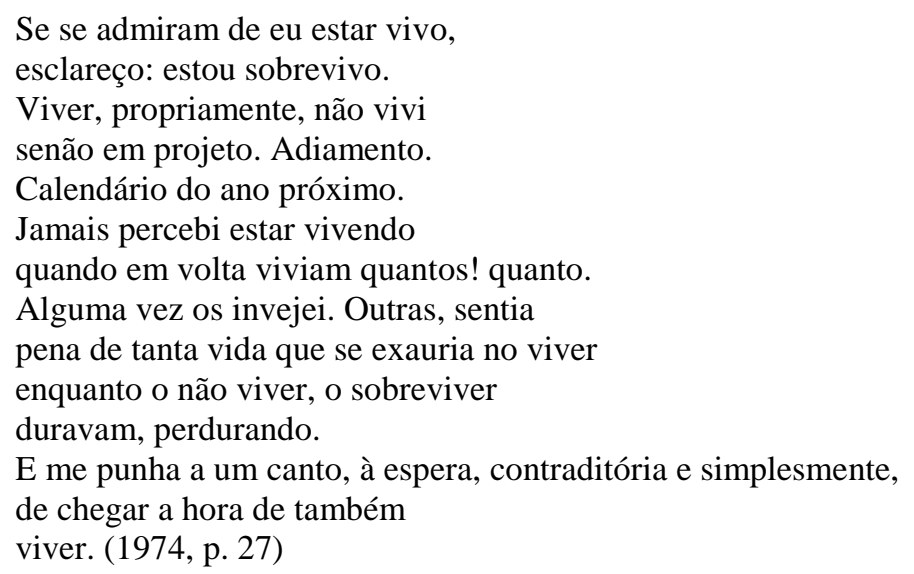

Estamos diante de um lamento de um eu-lírico cansado de postergar, esperar pela vida propriamente. Há muita diferença entre viver e sobreviver, já que uma pessoa que usufrui uma sobrevida não goza da mesma liberdade que outra que simplesmente vive. O sobrevivente é aquele que escapou da morte, mas que muitas vezes - como acontece com este eu-lírico vive cercado por ela, ou seja, deve evitar deslizes, manter-se na linha, caso contrário acaba a sua sobrevida. A tática de sobrevivência à ditadura militar do poeta Carlos Drummond de Andrade pode estar nas entrelinhas destes versos abaixo, pois neles o eu-lírico afirma ter primeiramente desistido, depois se recolhido, para, finalmente, tornar-se um sobrevivente.

\footnotetext{
Não chegou. Digo que não. Tudo foram ensaios, testes, ilustrações. A verdadeira vida sorria longe, indecifrável.

Desisti. Recolhi-me cada vez mais, concha, à concha. Agora sou sobrevivente.

Sobrevivente incomoda mais que fantasma. Sei: a mim mesmo incomodo-me. O reflexo é uma prova feroz. Por mais que me esconda, projeto-me, devolvo-me, provoco-me.

Não adianta ameaçar-me. Volto sempre,
} 
todas as manhãs me volto, viravolto

com exatidão de carteiro que distribui más notícias.

$\mathrm{O}$ dia todo é dia

de verificar o meu fenômeno.

Estou onde não estão

minhas raízes, meu caminho:

onde sobrei,

insistente, reiterado, aflitivo

sobrevivente

da vida que ainda

não vivi, juro por Deus e o Diabo, não vivi.

Tudo confessado, que pena

me será aplicada, ou perdão?

Desconfio nada pode ser feito

a meu favor ou contra.

Nem há técnica

de fazer, desfazer

o infeito infazível.

Se sou sobrevivente, sou sobrevivente.

Cumpre reconhecer-me esta qualidade

que finalmente o é. Sou o único, entendem?

de um grupo muito antigo

de que não há memória nas calçadas

e nos vídeos.

Único a permanecer, a dormir,

a jantar, a urinar,

a tropeçar, até mesmo a sorrir

em rápidas ocasiões, mas garanto que sorri,

como neste momento estou sorrindo

de ser-delícia?- sobrevivente. (1974, p. 27-28)

Esta última estrofe explicita a malandragem retórica do poeta, pois de antemão o eulírico declara ter confessado tudo e ter ciência de que permanecerá impune. O desplante desta afronta chega ao ponto de ele perguntar: "Sou o único, entendem?". Pergunta que será respondida alguns versos adiante quando afirmará: “Acabo de notar, e sem surpresa:/ não me ouvem no sentido de entender".

É esperar apenas, está bem? que passe o tempo de sobrevivência e tudo se resolva sem escândalo ante a justiça indiferente.

Acabo de notar, e sem surpresa: não me ouvem no sentido de entender, nem importa que um sobrevivente venha contar seu caso, defender-se ou acusar-se, é tudo a mesma nenhuma coisa, e branca. (1974, p. 29)

Nos versos que encerram esse poema, temos novamente uma referência à justiça, ou melhor, à falta dela, que imperava naquele momento, assim como já tinha sido exposto no poema "Diamundo". Enquanto o eu-lírico sobrevive, a justiça permanece indiferente, tão 
indiferente que sequer toma conhecimento das defesas ou acusações de um sobrevivente. "É tudo a mesma/ nenhuma coisa, e branca."

A utilização da cor branca na construção imagética deste último poema analisado tornará a aparecer em As impurezas do branco, no poema "Paisagem: como se faz", mais especificamente, na quarta estrofe:

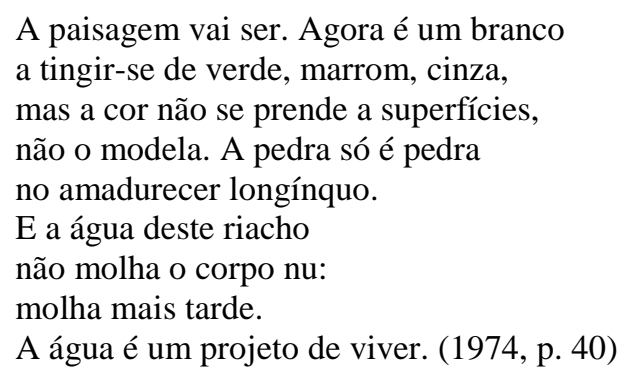

Também em "Paisagem: como se faz", podemos facilmente apreender a repetição da idéia de cancelamento, adiamento da outra vida a ser vivida. Antes tínhamos a promessa de uma vida (futuro) que viria depois da sobrevida (presente) do eu-lírico. Agora temos uma água que só molha mais tarde, pedras a amadurecer e uma paisagem que não é, será. A paisagem terá cor depois que passar o tempo do branco e de suas impurezas.

A recorrência da cor branca e a sua presença no próprio título deste livro poderiam ser frutos da intenção do poeta gauche de ironizar a situação política e social do Brasil daquela época, tendo em vista que, para muitas pessoas, o governo ditatorial estava sendo benéfico para o país. A ditadura era aparentemente um bom sistema de governo, impressão que não resistia a um olhar mais atento e aprofundado. Como o branco, que simboliza a pureza e a luminosidade, mas que também possui impurezas, imperceptíveis a olhares ligeiros.

Cabe lembrarmos que o Brasil realmente prosperou naqueles anos de grandes modificações e que os donos do poder utilizavam-se deste progresso para a defesa do governo ditatorial. Citamos novamente uma notícia resgatada por Elio Gaspari (2002, p. 472) em $A$ ditadura escancarada: "Segundo uma pesquisa do Gallup, 48\% dos paulistanos acham que seu nível de vida está subindo. Só 7\% dizem que está caindo”.

O bem-estar econômico da classe média dava sustentação aos generais, pois amenizava o mal-estar provocado pela falta de liberdade e pela tortura. Quem nunca presenciou alguém afirmar ter saudades da ditadura? Aqueles que já presenciaram sabem que a saudosa declaração termina com a frase: "aquele tempo é que era bom". Essas pessoas têm saudade do poder aquisitivo, da febre patriótica e da (falsa) ilusão de segurança daqueles tempos. Tempos brancos, que ocultavam impurezas. 
O posicionamento deste eu-lírico é também interessado em denunciar a paisagem política em que estava inserido, preocupação recorrente em Drummond, ou como constatou Buarque de Holanda (1978, p.185):

O exercício ocasional de um tipo de poesia militante e contencioso terá servido para purificar ainda mais uma expressão que já alcançara singular limpidez. Mas o impulso que o levaria a superar essa poesia militante não chegaria nele a abolir a preocupação assídua do mundo finito e das coisas do tempo.

Em 1973, Drummond, apesar dos sonhos frustrados e da ditadura militar, ainda se preocupava com o mundo finito e com as coisas do tempo, como podemos verificar em As impurezas do branco, no poema "Paisagem: como se faz". Leiamos os seguintes versos:

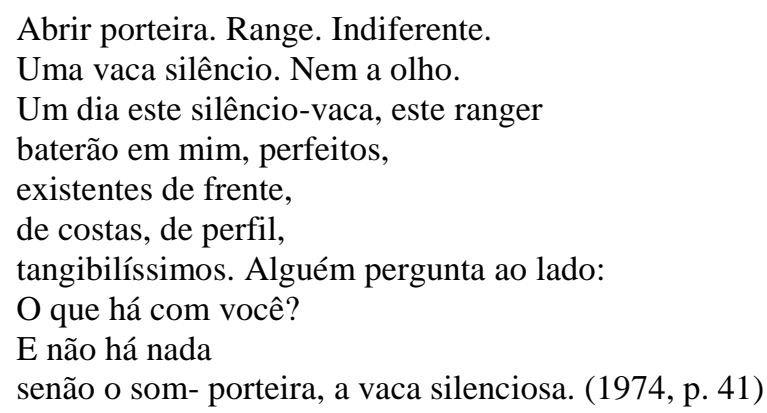

No começo do poema, o eu-lírico nos fala de uma paisagem que praticamente não existe, descolorida, branca, em que não há vida presente, apenas "paisagem retrospectiva" ou "tudo é mais tarde". Mas nesta penúltima estrofe, somos informados de que há uma vaca na paisagem, não uma vaca qualquer, mas uma "vaca-silêncio". Ou seja, uma inusitada imagem que simboliza o silêncio inerente às ditaduras, assim como a injustiça, a violência, a falta de liberdade. A violência e a submissão, por sua vez, estão sendo criticadas nos derradeiros versos do poema a seguir:

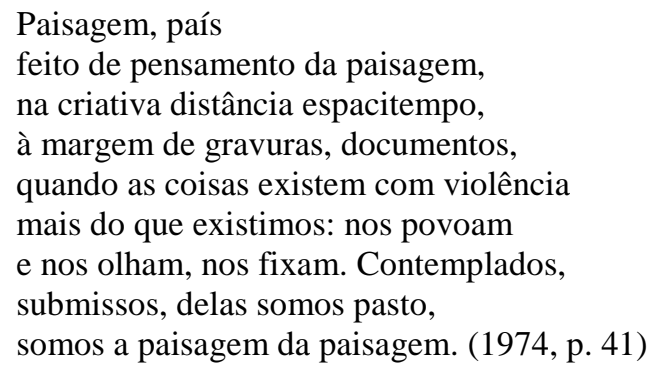

As coisas existiam com violência e, dessa forma, povoavam, olhavam e fixavam a todos, ou seja, todos existiam como uma paisagem morta, à margem de gravuras, documentos. Enfim, distantes de tudo aquilo que poderia levar à verdade e à justiça. O sujeito lírico irmana-se a todos aqueles que também são pasto da "vaca-silêncio", referida anteriormente no poema, a todos que compõem com ele essa paisagem da paisagem branca, que um dia se colorirá. 


\section{Concluindo...}

O mesmo poeta que compôs versos como os que encontramos em A rosa do povo (1945) publicou, em 1973, um livro esteticamente inferior àquele, o que talvez explique o fato de As impurezas do branco não ter sido reeditado novamente, nem receber a atenção da crítica.

As impurezas do branco não resiste a uma comparação com a poesia da grande fase de Drummond, mas possui méritos que fazem valer a sua leitura e que, por sua vez, auxiliam na compreensão do poeta. Um livro em que o poeta mineiro nos apresenta um eu-lírico por vezes grandiloqüente e que, dessa forma, critica e lamenta a ditadura brasileira quando ela ainda mantinha-se ferrenha no controle das liberdades.

O leitor de Drummond percebe na leitura de As impurezas do branco que há passagens em que o texto beira o panfletário, as quais denunciam a preocupação do poeta com o conteúdo da sua poesia. As atenções de Drummond estavam voltadas à denúncia da realidade da vida social brasileira, tão voltadas que acabaram negligenciando uma parte essencial da poesia, que é a forma, a linguagem.

Em alguns momentos de As impurezas do branco, podemos perceber que Drummond não acertou a mão quanto ao ritmo e à sintaxe, assim como cometeu alguns exageros experimentais. Deslizes que não invalidam a sua leitura, pois sempre encontramos o Drummond em Drummond. Apesar de seus defeitos, é neste livro que podemos ler versos como os de "Declaração em Juízo" e "Viver", a seguir:

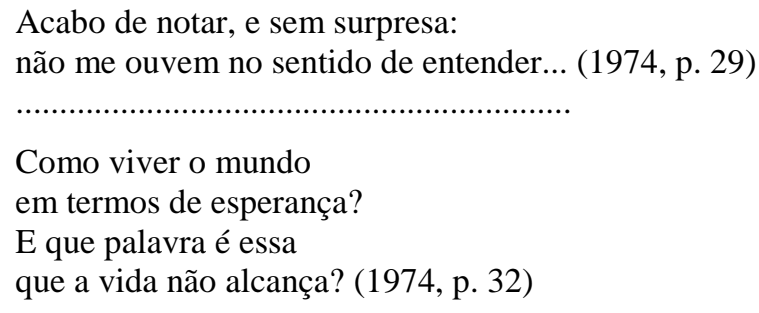

Para encerrar a conversa: neste livro, Carlos Drummond de Andrade driblou a desesperança, a censura, só não conseguiu ainda driblar o esquecimento.

\section{Referências}

ANDRADE, Carlos Drummond de. A Rosa do Povo. Rio de Janeiro: Record, 2000. 
. As impurezas do branco. Rio de Janeiro: José Olympio, 1974.

CAMILO, Vagner. Drummond: da Rosa do Povo à Rosa das Trevas. São Paulo: Ateliê, 2001.

CANDIDO, Antonio. O mundo desfeito e refeito. In: Recortes. São Paulo:

Companhia das Letras, 1996. p. 30-34.

FRANCO, Afonso Arinos de Melo. O predomínio dos atributos intelectuais. In: BRAYNER, Sônia (Org.). Carlos Drummond de Andrade. Rio de Janeiro: Civilização Brasileira,1978. p. 83-87.

GASPARI, Elio. A Ditadura Escancarada. São Paulo: Companhia das Letras, 2002.

HOLANDA, Sérgio Buarque de. Rebelião e convenção. In: BRAYNER, Sônia (Org.). Carlos Drummond de Andrade. Rio de Janeiro: Civilização Brasileira,1978. p. 184-191.

LIMA, Luiz Costa. Lira e Antilira. Rio de Janeiro: Civilização Brasileira, 1968. 